\title{
A Review on Phytochemicals (Including Essential Oils and Extracts) Inclusion in Feed and Their Effects on Food Producing Animals
}

\author{
Fabio Granados-Chinchilla* \\ Centro de Investigación en Nutrición Animal, Universidad de Costa Rica, Universitaria Rodrigo Facio San José, Costa Rica
}

Submission: July 26, 2017; Published: September 22, 2017

*Corresponding author: Fabio Granados-Chinchilla, Centro de Investigación en Nutrición Animal (CINA), Universidad de Costa Rica, 11501-2060. Ciudad Universitaria Rodrigo Facio San José, Costa Rica, Tel: +506 2511-2028; Fax: +506 2234-2415;

Email: fabio.granados@ucr.ac.cr

\begin{abstract}
This report is intended to give an overlook at the essential oil and phytochemical applications on food producing animals when applied to feed. The first part aims to illustrate that gas chromatography coupled with mass detection (GC/MS) has become powerful tool for phytochemistry and some examples of typical constituents found in essential oils; relevant cases are mentioned (especially those oils extracted from plants found in tropical regions). Secondly, a brief overview of the most recent research encompassing the in vitro ability of some essential oils and phytochemicals to limit food borne bacterial growth is depicted. Finally, herein the reader will find some recent and relevant examples of essential oils and phytochemicals that are commonly used as additives in the feed, based on their beneficial properties for the animal (with particular attention as potential substitutes for antibiotic growth promoters). Hence, the review focuses specifically on three parts:

i. chemical composition and analysis of plant derived active substances

ii. In vitro antimicrobial activity of plant derived substances and

iii. essential oils and extracts applications in feed including poultry, cattle, rabbits, fish, pigs, and examples of other species.
\end{abstract}

Keywords: Essential oils; Plant extracts; Phytochemicals; Animal feeds; Food producing animals; Antimicrobial activity; Chemical composition

\section{Introduction}

Essential oils are aromatic hydrophobic liquids extracted commonly by hydro distillation from a diverse number of plant parts; this includes but is not limited to flowers, buds, seeds, leaves, twigs, bark, wood, fruits, receptacles and roots [1]. Specific compounds of interest can be obtained from processing plant tissue and using separation techniques. However this approach is expensive, significant amounts of plant material are needed (unfavorable for exotic plant species), and reduced yields are usually obtained. Hence, when on high demand, or the desired compound is identified and isolated, it can be synthetically manufactured. These oils often contain diverse families of compounds which convert them in complex chemical mixtures [2]. Other biochemically active groups of compounds (e.g. polyphenols, glycosides) are usually extracted directly from the plant tissue with solvents (e.g. methanol, ethanol, ethyl acetate). A particular compound or the resulting mixture of said compounds may be biosynthesized by the plant to protect it from bacteria, fungal infections or even insects. For example, essential oils have been described to possess antimicrobial, antiparasitic, antioxidant, immune modulating, and anti-inflammatory properties and hence they have been used in animal nutrition [3]. The focus of this review will only be the antimicrobial capability of different phytochemicals.

Several essential oils are still being investigated to incorporate them into the feed as substitutes for antimicrobial growth promoters, especially since the latter have demonstrated a significant capacity to induce resistance in bacteria as well as persistence and contamination of the environment [4]. Some of these oils because of their availability, yield and distribution have found widespread use in animal nutrition; such is the case of oregano (Origanum vulgare L.) [5].

An interesting review that lists the most commonly used herbal additives in animal feed and their main effects on animals can be found in Kumar and coworkers work [6]. On another hand, few papers have detailed in-depth the antimicrobial 
effects of essential oils and the molecules responsible for said activity. Lopez-Romero and coworkers held accountable changes in the hydrophobicity, surface charge, and membrane integrity with the subsequent $\mathrm{K}^{+}$leakage as the most common modes of action of citronellal, carveol, and carvone on relevant and model bacteria such as Escherichia coli and Staphylococcus aureus [7]. Furthermore, Saeidi and coworkers demonstrated that the alcoholic extract of different natural plants including Myrtus communis L., Amaranthus retraflexus L., Cyminum cuminum L., Marrubium vulgare L. and Peganum harmala L. were effective against the extended-spectrum beta-lactamase-producing E. coli isolates, which harbor the TEM genes [8].

Finally, the agriculture and animal productive sectors are constantly in search for new additives to improve growth (and hence, economic return) and fight disease [9]. In this sense, phytochemicals including essential oils and plant extracts (and the compounds therein) may present themselves as a possibility.

\section{Discussion}

\section{Recent description of phytochemicals in bearing plants and assessment of antimicrobial activity}

\section{Chemical composition and analysis of plant derived} active substances: Phytochemical analysis requires identification of the substance or substances that are present to assess the potential or applications they can be used for. No extract, essential oil or plant-derived substance analysis is complete without fingerprinting or at least identification of the major players in the complex mixtures that are usually obtained from the plant material. A widespread practice in essential oil research; chemical analysis (usually chromatography) followed by further in vitro or in vivo assays to demonstrate other properties (e.g. antimicrobial, antioxidant) [1]. For example, Coffee and coworkers found mostly tannins and polyphenols, saponins and cyanogenic glycosides in three bamboo species (Bambusa vulgaris Schrad. ex J. C. Wendl, Bambusa ventricosa McClure, and Oxytenanthera abyssinica A. Rich.) from Ghana [10]. Zagorcheva and coworkers assayed lavender (Lavandula angustifolia Mill.) finding 32 volatiles with benzaldehyde and $\beta$-fresene being the most prevalent they also compared their characterization with the ISO standard and tested the organic extract of the inflorescence [11]. De Falco and coworkers characterized essential oil of oregano (Origanum vulgare. subsp. vulgare L.) plants growing in single and binate rows. This spatial distribution seemed to affect oil composition as plants grown in individual rows was rich in sabinene, while plants grown in double rows were more abundant in ocimene (as determined by GC and GC/MS) [12]. In this scenario, gas chromatography with mass detection has become an important tool in the toolbox for essential oil analysis [13]. However, both oils were effective, particularly towards Bacillus subtitlis and B. cereus. The former Last paper exemplifies how a large number of factors may affect essential oil composition. In fact, any edaphoclimatic change impacts the quality and composition of the extract. Our study with two Psidium species reflects this as rainy season and dry season essential oil gathered from the same sampling regions is altered, this is particularly the case for compounds in smaller quantities [14]. Furthermore, a fascinating and recent research has focused on the influence of genotypes and environment over Psidium guajava L. essential oil. Twenty-two genotypes were analyzed observing differences in essential oil composition among individual genotypes. Then, the authors concluded that environmental factors do not alter primary compounds substantially; making P. guajava adequate for breeding programs [15]. Arjouni and coworkers reported the chemical composition of leaves, wood, and cones essential oil from Cupressus atlantica Gaussen using GC and GC/MS [16]. In the leaves, the main components were found to be trans Muurola-4 [14], 5-diene (31.2\%), $\alpha$-pinene (18.1\%) and $\alpha$-phellandrene (6.78\%). Principal components from the cones and wood essential oil, included $\alpha$-pinene $(56.6 \%-54.55 \%)$ and $\alpha$-phellandrene (7.1\%-15.7\%). Béjaoui and coworkers described essential oil from Origanum vulgare subsp. glandulosum Desf. at different phenological stages (i.e. vegetative, late vegetative, and flowering) [17]. The authors demonstrated that flowering stage produces a much lower oil yield. GC and GC/MS were used to analyze major components that ranged as follows: carvacrol (61.08-83.37\%), p-cymene (3.02-9.87\%), and $\gamma$-terpinene (4.13-6.34\%). Boligon and coworkers used GC/MS to assess the essential oil of Guazuma ulmifolia Lam. and identified thymol (20.97\%), carvacrol (13.76\%), eugenol (10.13\%), spathulenol (7.09\%), $\beta$-caryophyllene (6.74\%), sabinene (5.18\%), globulol (5.56\%), $\gamma$-terpinene (3.27) and $\alpha$-copaene (3.17\%) as the main components [18]. On another hand, Cruiz Buhian and coworkers used ethanolic extracts from Muntingia calabura L. leaves and stems to assay against $S$. aureus, B. Subtilis, E. coli and C. albicans which exhibited varying degrees of antimicrobial activity [19]. The extracts showed the highest activity against C. albicans, $S$. aureus, and P. aeruginosa. The authors report flavonoids, saponins and tannins to be present in both extracts. Hajdari and coworkers analyzed the essential oil from Pinus peuce Griseb. Twigs and needles from two different regions from a national park in Kosovo. GC/MS found $\alpha$-pinene (needles: 21.6-34.9\%; twigs: 11.0-24\%), $\beta$-phellandrene (needles: 4.1-27.7; twigs: 29.0 $49.8 \%$ ), and $\alpha$-pinene (needles: $10.0-16.1$; twigs: $6.9-20.7 \%$ ) to be the main compounds [20]. The authors further demonstrate that microclimatic changes from a scheme region affect the profile of the oil. Hanafi and coworkers analyzed cumin (Cuminum cyminum L.) and coriander (Coriandrum sativum L.) fruits [21]. Constituents of cumin oil were identified as $\gamma$ - terpinene (22.7\%), $\beta$-pinene (19.2\%), cumin aldehyde (18.0\%), p-cymene (11.5\%), whereas linalool (70.43\%) was found to be the most abundant component in coriander oil. Takayama and coworkers extracted essential oil from Rosmarinus officinalis L. from Brazil and analyzed it using GC/MS finding as main constituents cineole (28.5\%), camphor $(27.7 \%)$ and alpha-pinene (21.3\%) [22]. Furthermore, the authors demonstrated an antioxidant effect in an ethanol-induced gastric ulcer in vivo murine model. Siddique and coworkers recently described by GC/MS the essential oil and 
the fatty acid profile of Stevia rebaudiana (Bert) Bertoni [23]. The authors found $\alpha$-cadinol (2.98\%), caryophyllene oxide $(1.23 \%)$, and (-)-spathulenol $(2.21 \%)$ and $\beta$-guaiene $(0.32 \%)$ to be the most important compounds present. The authors also used gasliquid chromatography and assessed as much as $86.50 \%$ palmitic acid. Plant derived fatty acid could easily be an unexplored source of fat to include in animal feed, especially those parts of the plant that are considered waste after other uses (e.g. cashew outer shell after removal of the nut or stevia leaves after steviol glucoside extraction).

\section{In vitro antimicrobial activity of plant derived substances}

A standard approach for phytochemicals, especially essential oils, is assaying their capacity against food borne bacteria, especially true since bacterial resistance against antimicrobial has been an issue for quite some time [24]. Some essential oils have indeed demonstrated a high ability to eliminate bacteria or stunt bacterial growth. However, data seems to indicate a mild capacity of essential oils to act against real pathogens (e.g. Salmonella enterica serovar Typhimurium) when added to animal feed ingredients (i.e. feather meal, avian blood meal, porcine meat and bone meal, and poultry by-product meal [25]. The previous data is in line with our research: when applying Costa Rican guava leaves, lemon grass and tangerine essential oils on meat and bone meal previously inoculated with $S$. Typhimurium (unpublished data); we observed a moderate efficacy of Salmonella elimination. However, Bianchini and coworkers assayed 25 different essential oils over $S$. Typhimurium and Penicillum roqueforti and demonstrated that, in vitro, the best inhibitors for Salmonella were cinnamon and thyme essential oil at 0.05 $\mathrm{mL} / 100 \mathrm{~mL}$ and $0.1 \mathrm{~mL} / 100 \mathrm{~mL}$, respectively [26]. P. roqueforti was best inhibited by cinnamon and spearmint essential oil at $0.01 \mathrm{~mL} / 100 \mathrm{~mL}$ and $0.5 \mathrm{~mL} / 100 \mathrm{~mL}$. Furthermore, the authors assayed the oil activity on extruded pet food and interestingly, only $0.1 \mathrm{~mL}$ cinnamon essential oil/100 g pet food, used as part of the pellet coating, could reduce Salmonella enterica serovar Typhimurium significantly. Another example in which although in vitro assays may give a general idea of antimicrobial activity feed processing may interfere with the capacity of the oil to perform. This report is interesting since $P$. roqueforti is a toxin producing fungi (i.e. mycophenolic acid, roquefortine $\mathrm{C}$ ) which are more likely to infect feed ingredients such as silages. Hence, the authors' in vitro results, though ineffective on extruded pet food, could be assayed on P. roqueforti contaminated silage.

Béjaoui and coworkers described antibacterial oil extracted from Origanum vulgare subsp. Glandulosum Desf. when tested against three Gram-positive and two Gram-negative bacteria. Bacillus subtilis was found to be the most sensitive strain [17]. Interestingly, the oil still exhibited limited activity against an Ampicillin-resistant Pseudomonas aeruginosa strain. Active oils extracted from Origanum vulgare represent an inexpensive source of natural antibacterial substances since oregano plants distribution may be considered cosmopolite and easy to grow.
Essential oil from Guazuma ulmifolia Lam. showed good activity against P. aeruginosa and S. aureus (MIC of 62.50 and $125.00 \mu \mathrm{g} /$ $\mathrm{mL}$, respectively), and moderately activity against $E$. coli and $S$. epidermidis (MIC of 500 and $750 \mu \mathrm{g} / \mathrm{mL}$, respectively) [18].

Rajendran and coworkers extracted oil from curry tree leaves (Murraya koenigii L.), which mainly was based on linalool, elemol, and geranyl acetate [27]. The oil has a maximum zone of inhibition ability against Corynebacterium tuberculosis, Pseudomonas aeruginosa, Streptococcus pyogenes, Klebsiella pneumoniae and Enterobacter aerogenes. Saeidi and coworkers effectively used the alcoholic extract of wild rue (Peganum harmala L.) seeds was very efficient against extended-spectrum beta-lactamase-producing $E$. coli isolates harboring the TEM gene [28]. Recently, Mostafa and co-workers demonstrated that pomegranate (Punica granatum L.) and clove (Syzygium aromaticum L.) extracts were effective against common food borne pathogens (i.e, B. cereus, S. aureus, E. coli, Salmonella enterica serovar Typhi, P. aeruginosa) [29]. Data which speaks of the possible use of these plants as natural alternatives to prevent food borne diseases, preserve foodstuffs and extend shelf-life while avoiding health hazards of antibiotics. Ginovyan and coworkers demonstrated that crude acetone and hexane extracts of St. John's-worts (Hypericum alpestre Steven) and acetone extract of burnet-bloodworm (Sanguisorba officinalis L.) inhibited the growth of P. aeruginosa even at $64 \mu \mathrm{g} /$ $\mathrm{mL}$ concentration [30]. Mith and coworkers tried different commercial essential oils against food borne pathogenic bacteria (Listeria monocytogenes, S. Typhimurium, and enterohemorrhagic Escherichia coli 0157:H7) and food spoilage bacteria (Brochothrix thermosphacta and Pseudomonas fluorescens) [31]. Essential oils of cinnamon, oregano, and thyme showed stronger antimicrobial activities with minimal inhibitory and minimum bactericidal concentrations $\geq 0.125 \mu \mathrm{L} / \mathrm{mL}$ and $\geq 0.25 \mu \mathrm{L} / \mathrm{mL}$, respectively. Ozogul and coworkers published an extensive work regarding the effects of several essential oils including pine, eucalyptus, thyme, sage tea, lavender, orange, laurel, lemon, myrtle, lemon, rosemary and juniper over common foodborne pathogens [32]. The bacterial species tested included Escherichia coli, Salmonella Paratyphi A, Klebsiella pneumoniae, Yersinia enterocolitica, Pseudomonas aeruginosa, Aeromonas hydrophila, Campylobacter jejuni, Enterococcus faecalis, and Staphylococcus aureus. The authors found that the most important compounds found in the essential oils were monoterpenes hydrocarbons, $\alpha$-pinene, limonene; monoterpene phenol, carvacrol and oxygenated monoterpenes, camphor, 1,8-cineole, eucalyptol, linalool and linalyl acetate. Juniper and pine oils were found to be the least and most active oils against bacteria, respectively. Venkatesan and coworkers recently described the antioxidant, radical scavenging and antimicrobial capability of Terminalia chebula Retz. (Black or chebulic myrobalan) Bark Extracts after its extraction with several organic solvents. The authors performed after each extraction presumptive drop tests to screen for different groups of compounds (e.g. alcaloids, flavonoids, terpenoids). Acetone extract was found to be the more effective 
against E. faecalis, S. aureus, and B. subtilis, V. vulgaris, S. Typhi, and Shigella sonnei. Furthermore, acetone extract was analyzed by GC/MS; ferulic acid, galic acid, $\alpha$-santalol, was identified as the predominant components [33]. A similar approach was used by Manjula and Chitra but applied for Calotropis gigantean (L.) R. Br. ex Schult. (Crown flower) and Curcuma neilgherrensis is Wight ("Kattukalvazhai"), the authors found more compounds in a methanolic extract than acetone or petroleum ether [34]. Salaheen and coworkers reported the activity of bioactive extracts (consisting mainly in flavan, flavanone, flavones, glucuronides, glucosides, quinolones, catechol, coumarin, phenols, luteolines, tannins, quercetin, chlorogenic acid, ellagic acid, gallic acid, and xanthoxic acid) from berries [blackberry (Rubus fruticosus L.) and blueberry (Vaccinium corymbosum L.)] by-products against pathogenic, food borne bacteria such as Salmonella Typhimurium. The authors reported an increase of injured bacterial cells by ca. $50 \%$ and a decrease in bacterial surface hydrophobicity, auto-aggregation, cellular motility, and invasion capability into cultured INT407, HD11, and DF1 cells. Several genes responsible for the expression of type III secretion system (i.e. hilA, hilC, invA, invF, $\operatorname{sir} A$, and $\operatorname{sir} B$ ) were significantly downregulated [35]. The same research group also extended their research to include other food borne microorganisms. The authors demonstrated that the berry extract inhibited growth of L. monocytogenes and the enterohemorrhagic Escherichia coli serotype 0157:H7 [36]. Interestingly, promoted growth of Lactobacillus strains [36]. This data demonstrate a potential in food processing and safety. Feed products based on whey or silages could benefit from both reported effects. Then, the research was extended to yet another pathogen; Campylobacter jenuni. Physicochemical and virulence genes were both affected by the extract [37]. In this occasion, the authors reported an economic approach for extraction [37]. A relevant feature since usually from natural sources is usually expensive and can hinder scale-up. Care must be taken to avoid confounding effects that the solvent may input. For example, during, in vitro antimicrobial diffusion disk tests a usual practice is to apply the extract and let evaporate before applying to the strain or using a negative control, in parallel, using just the solvent. Therefore, practices to evaporate the solvent to dryness (e.g. vacuum, nitrogen positive pressure) are to be considered before a direct application in food or feed, as solvents produce toxicity. On another hand, other researchers have opted to use other extraction technologies such as a critical super fluid (especially $\mathrm{CO}_{2}$ ) to avoid solvents altogether [38].

Is imperative to obtain this type of data not only for pathogenic bacteria but especially for those pathogens which can be vectors of disease using feed or food as vehicle (food borne diseases). These pathogens have a profound effect on the food chain and overall production. Bacterial resistance to traditional antibiotics has worsened pathogen colonization and complicated treatment, several alternatives are being evaluated including essential oils and other phytochemicals. Yang and coworkers and, more recently, the research group lead by Castillo-López wrote comprehensive reviews that focus the use of phytochemicals as in-feed alternatives to antimicrobials [24,25].

\section{Essential oils and extracts applications in feed}

Since the animal production has been historically responsible for a significant amount of the usage of antimicrobials and has administered them usually through feed is of relevance to assay the efficacy of phytochemicals when directly applied to the animal feed. The effects of the inclusion of these natural products is of exceptional importance since feed palatability, animal physiology and final consumer products derived from these animals (e.g. eggs, meat, cheese, and milk) may be altered and are paramount production-wise.

Additionally, essential oils and other phytochemical compounds directly applied to feeding stuffs can improve shelf life and safety of the feed. There is still an ongoing discussion regarding the usage of antibiotics in feed as growth promoters. The primary goal here is to modulate gut micro biota to improve host metabolism and reduce competition. Hence, the effect that phytochemicals exert on growth performance is attractive as a substitute therapy for common antibiotics. In this section, we will discuss the most recent research devoted to clarifying the effect of phytochemicals (especially, essential oils) on animals. The reader is encouraged to read other recent reviews [40-42].

Natural products are added to feeds with two different ends, including scarcity of feed ingredients and antibiotic therapy substitution. For example, hesperidins are the most predominant flavonoid in the tangerine peel, this byproduct may be included in feed as part of a complete feeding ration (based on citrus pulp nutrition) and as a source for bioactive substances. For example, other researchers have evaluated Psidium leaves potential as forage [43], tried to incorporate the leaf meal or crude extract of $P$. guajava into broiler chicken diets [44] and even have introduced them into rat diets [45]. Animal feed supplementation may have not only an intrinsically impact on food producing animals' growth promotion but may also affects the final product that reaches the consumer (e.g. eggs, meat, milk and so on).

A recent example of enrichment of traditional products by the incorporation of essential oils has been reported. For example, Shalaby and coworkers recently reported the preparation of cheese sauce with essential oil of cardamom [Elettaria cardamomum (L.) Maton] and shallots (Allium ascalonicum L.), among others [46]. Both essential oils have been reported to have antibacterial and antifungal activity. In yet another example, Lejonklev described that silages produced from red (Trifolium pratense L.) or white clover (Trifolium repens L.) reduced bio hydrogenation in vitro when compared to silages from rye grass (Lolium perenne L.) [47]. The author also administered caraway (Carum carvi L.) seeds and oregano (Origanum vulgare) essential oils as an in-feed additive. Though no effect over methane emission, milk yields or $\mathrm{C}_{18}$ fatty acid content was observed, terpene carry-over was observed from feed to bovine milk. Also, the author described transfer when the essential oils were 
administered through direct infusion to the duodenum and by vapor inhalation $[48,49]$. Though feed inclusion is the most convenient way to introduce additives, especially when treating numerous groups of animals simultaneously, this exemplifies other administration routes are possible for essential oils. Not only the inclusion of essential oils in dairy can be used to obtain new products, but it could help introduce bioactive substances (e.g. terpenes) that may improve the shelf life of the commercial product.

Several methods have been used to assess bacterial or fungal inhibition activity, in this regard, Krisch and coworkers have written a thorough review [50]. Furthermore, recent attention has been drawn toward fungi, especially those from the genus Alternaria, Aspergillus, Penicillum, Fusarium since these are both spoilage-related microorganisms and potential mycotoxin producers. The reader is also encouraged to read the work by Tongnuanchan and Benjakul which cite the most common techniques in oil extraction and purification [51]. This review also states several examples on how can essential oils can be incorporated into packaging and foods with emphasis in extension of shelf life and preservation. In this regard, Shahavi and coworkers demonstrated the improve efficiency of a stable nano emulsion (50 $\mathrm{nm}$ droplet size) from clove oil and its effectiveness against E. coli and B. cereus. [52].

Fruit and vegetable processing usually generate considerable waste. Hence it is not unusual to industries to include primary activities by-products in their animal feed. For example, apple and grape pomace or citrus peels (e.g. in Costa Rica a common practice is to convert the fibrous pineapple processing byproducts into silage). Including polyphenols, carotenoids, phytosterols and, at the same time, added value. This byproduct inclusion in feed help reduce waste and ameliorating environmental impact. This issue is contemplated in a review by Kasapidou and coworkers [58]. Not only has several of these by-products been described as nutritional and improved feed quality but have also been described as functional.

Moreover, at least one case of parasite resistance has been described toward thymol and eugenol. Crithidia bombi, a Bombus spp. common trypanosome parasite was recently described to develop resistance to both phytochemicals[54]. This finding has severe impacts on the effectiveness of oils as alternative therapeutic agents against microorganisms [55]. Different phytochemicals have been transformed into feed additives (in the form of essential oils, organic/aqueous extracts or even powders) and tested in a number of animal species. These phytochemicals serve a sensory, technological purpose or may have an effect on feed conversion or the quality of animal products [56]. An increase in search for alternatives for antibiotic growth promoters can be expected as from January 1st, 2017 the FDA (in line with rules that have existed in the European Union since 2006) has made compulsory the retirement of this substances as additives in feed (except for coccidiostats) for growth promotion purposes [57].
Poultry: Jiang and coworkers recently proved that growth performance could be increased, during the starter period of broiler chicks substituting antibiotics for tangerine peel extracts [58]. Moringa olifera Lam. leaf has also been introduced in feed for laying hens, and an improved feed conversion has been noted. However, Lu and coworkers also observed adverse histopathological findings in renal tissue when $15 \mathrm{~g} / 100 \mathrm{~g}$ leaf was included [59]. Also, higher feed conversion ratio and lower egg production compared with those in control group was observed. In contrast, $5 \mathrm{~g} / 100 \mathrm{~g}$ inclusion resulted in deeper yolk color. These results evidence that despite plant derived products, which may be regarded as safe, their incorporation into animal diets must be subjected to studies to observe possible anti-nutritional or adverse effects. In both cases, authors have linked these effects due to flavonoids $[58,60]$. Mohammadi and coworkers demonstrated that the inclusion of $500 \mathrm{mg} / \mathrm{kg}$ and $300 \mathrm{mg} / \mathrm{kg}$ of clove essential oil, respectively, improved weight gain and feed conversion in broilers [61]. The supplementation increased Lactobacillus counts and decreased Escherichia coli counts in caecum when compared to the control treatment. The authors state that eugenol may be responsible for the effects accounted for that included highest feed intake, weight gain and improved feed conversion ratio. They also noted that Lactobacillus can cause changes in villi of the small intestine and is effective in improving broiler growth performance. The reader is referred to a review article by Valenzuela-Grijalva and coworkers regarding growth promotion, carcass and meat quality focused on poultry and swine [62]. Therein, the authors specifically tackle several concerns about including phytochemicals into the feed. Peek and coworkers used an extract from purple coneflower (Echinacea purpurea (L.) Moench), a $\beta$-glucan-rich extract from Shiitake (Lentinula edodes (Berk.) Pegler), betaine, curcumin from turmeric (Curcuma longa L.) powder, and carvacrol to try on chickens inoculated with $E$. coli [63]. However, none of the tested phytochemicals reduced mortality significantly, nor did they improve recovery from colibacillosis lesions. However, although negative results were obtained for the phytochemicals, this trial exemplifies an in vivo experiment using plant derived substances. Anticoccidial effects from oregano oil in broilers has been previously investigated and though there is in fact in vivo evidence for this activity (oocyst counts in feces), is lower than that of observed in birds fed with a coccidiostat [64]. The same authors demonstrated an increase in feed conversion though pre-slaughter weight, carcass yield, or serum IgG levels were unaltered. Though mainly polyphenols have been attributed free radical scavenging activity in poultry (and other animals), antimicrobial properties for polyphenols have been documented [65]. A thorough review on essential oil in chicken production was written by Adaszyńska-Skwirzyńska and Szczerbińska [66]. In a thought-provoking paper, Çabuk and coworkers compared a mixture of essential oils (24 mg oil/ $\mathrm{kg}$ feed) with avilamycin (10 mg/kg feed) as a dietary supplement and their effects on egg production in quail [67]. The essential oil mixture consisted of 6 different herbs: oregano (Origanum sp.), laurel leaf (Laurus nobilis L.), sage leaf (Salvia triloba L.), myrtle 
leaf (Myrtus communis L.), fennel seeds (Foeniculum vulgare Mill.), and citrus peel (Citrus sp.). Both treatments increased egg production in quail. Egg production was similar for both treatment groups. Moreover, the authors found no differences between the treatment groups about egg weight. Feed intake was not affected by any supplement, whereas both significantly improved feed conversion ratio. This research offers evidence toward a future for essential oil application substituting antimicrobial at least as feed supplement at least for birds. Küçükyilmaz and coworkers recently applied lavender (Lavandula stoechas L.) oil for a 21day feeding period [68]. The bodyweight of chicks fed with 24 $\mathrm{mg}$ oil/kg feed was higher when compared to the control. No differences in feed intake, feed conversion ratio and mortality among treatments a relative reduction was observed in liver weight. The authors not only conclude that lavender essential oil can be used as a growth promoter in broiler nutrition, but they also indicate potential improvements in breast meat quality. Rendon and coworkers applied an essential oil blend containing capsaicin, carvacrol, and cinnamaldehyde on broilers [69]. A $400 \mathrm{mg} / \mathrm{kg}$ antibiotic growth promoter was compared to a diet containing $150 \mathrm{mg} / \mathrm{kg}$ oil based on a finisher feed. Interestingly, no significant differences were found in body weight gain, feed consumption, feed efficiency, dressing percentage, and livability. Shorter jejunal villi heights and deeper crypts were observed in the group treated with essential oils, this, in turn, associated with an improved nutrient absorption capacity in the animal. In this scenario, the authors state that essential oil phenolic compounds may facilitate intestinal cell turnover and reduction of adhesion capacity by pathogenic bacteria Salaheen and coworkers recently provided evidence that the colonization in broiler cecum a food borne pathogen as Campylobacter jenuni can be controlled by bioactive phenolics extracted from blackberry

(Rubus fruticosus L.) and blueberry (Vaccinium corymbosum L.) byproducts/pomaces. The phenolic extract also demonstrated a complete inhibition of the C. jejuni marker strain in drinking water with a potential for reduced horizontal transfer in poultry flocks. Expression of genes such as mreB (a gene which produces a actin homologue responsible for the control of shape in rodlike bacteria) was found to be downregulated. These findings hint toward a possible application of berry phenolic extracts against enteric pathogens in poultry gut [70]. The diversity of phytochemicals employed among poultry is further exemplified by the review by Aćimović and coworkers who included the usage of plants from the Apiaceae family. The text explores the usage of caraway, anise, coriander and fennel to improve performance parameters of poultry (broiler chickens and Japanese quail nutrition) and the prevention of diseases (including their mode of action) [71].

Cattle: Several investigations have been devoted to incorporate phytochemicals in ruminant diets. Here, rumen plays a relevant role when considering the overall effects expected from an additive base on phytochemicals. However, Oskoueian and coworkers demonstrated with their research several favorable effects of flavonoids on cattle: incorporation 4.5 g flavone, myricetin, naringin, catechin, rutin, quercetin, and kaempferol per $g$ of substrate generally decreased: the dry matter degradability, methane production, total volatile fatty acids concentration, the activities of carboxymethyl cellulase, filter paperase, xylanase, and $\beta$-glucosidase, purine content, population of rumen microbes (including protozoa and methanogens) and the efficiency of microbial protein synthesis [72]. This is relevant since efforts have been made to measure methane production by livestock and introducing diet alternatives (in our laboratory's case, using different types of forages) to suppress said environmental impact especially affecting countries with intensive production systems [73]. Joch and coworkers recently assayed eugenol, carvacrol, citral, limonene, 1,4-cineole, p-cymene, linalool, bornyl acetate, $\alpha$-pinene, and $\beta$-pinene (at a concentration of $1000 \mu \mathrm{g} / \mathrm{L}$ ) incubation with rumen fluid with a forage and concentrate substrate and demonstrated that from these oils, bornyl acetate did not inhibited volatile fatty acid production but diminished methane production [74]. The authors compared their results with a positive control using monensin proving that bornyl acetate exceeded the coccidiostat's effects. Vakili and coworkers, more specifically, demonstrated that cinnamon and thyme essential oils could be used as rumen fermentation modifiers without altering blood metabolism, even after high diet inclusion (i.e., $5 \mathrm{~g} / \mathrm{d} / \mathrm{animal}$ ) [75]. This is again an interesting study since in vivo data was obtained. On the other hand, ferulic acid ( $6 \mathrm{mg} / \mathrm{kg}$ body weight fed during 30 and 60 days) has been used during steer feed looting to improve meat quality and shelf-life. The authors noted an improvement in fatty acid profiles (especially $\mathrm{C}_{15: 0}, \mathrm{C}_{14: 1}, \mathrm{C}_{18: 2}$ ) IPUFA [polyunsaturated fatty acids] and omega-3,-6). Supplementation did not affect meat relevant parameters such as moisture, intramuscular fat, $\mathrm{pH}$, water holding capacity and color. However, more tender meat with higher sensory acceptance characteristics was attained after treatment. Interestingly, the results were compared to, the $\beta_{2}$ adrenergic agonist; zipaterol with ferulic acid showing improved outcomes. The reader is encouraged to read a recent review written by Islam and coworkers regarding antioxidant and antimicrobial applications of plant derivatives for meat products [76]. In a daring paper, Barreto Cruz and coworkers used glycerin and essential oils as substitution for corn, in feed for crossbred bulls. Essential oil from cashew (Anacardium occidentale L.) and castor (Ricinus communis L.) were tested ((up to $3 \mathrm{~g}$ oil/animal/day) [77]. The authors observed no effect of glycerine and essential oil addition on total blood cholesterol, triglycerides, haemogram, leukogram and plasmatic proteins. Furthermore, corn replacement by glycerine and essential oils addition did not affect carcass weight, dressing and conformation, carcass length and cushion thickness. This is relevant since corn is a relative expensive ingredient and some countries may find they are lacking the ingredient due to scarcity or import hindrances and, in turn, may want to appeal to local species and other practices to counteract this void. For example, our results show that cashew outer shell demonstrates good digestible and 
metabolizable energy values that justify a possible application in animal nutrition (unpublished results). Furthermore, extracted oil from the seed shows an excellent source of unsaturated fat and essential oil from the leaves and fruits show antioxidant potential (unpublished results). Gunal and coworker's used anise, cedar wood, cinnamon, eucalyptus, and tea tree oils and incubated them with ruminal fluid. Except for the case of the cinammon oil treatment, the proportions of acetate, propionate, and acetate to propionate ratios were not affected by the addition of the essential oil [78]. Addition of cedar wood, cinnamon and tea tree oils, reduced total volatile fatty acids concentrations regardless of dose level and all oils reduced $\mathrm{C}_{18: 0}$ and trans $\mathrm{C}_{18: 1}$ (both products of bio hydrogenation). Conversely, both linolenic acid and ammonia nitrogen increased after treatment. Velandia Valero and coworkers used propolis and essential oil (from cashew and castor) in feedlot Bulls as two independent diets [79]. The authors demonstrated that propolis can be successfully applied to feed as an ingredient without sacrificing animal performance, apparent digestibility, carcass characteristics or meat quality. Kolling and coworkers described the feeding intake of Holstein heifers after the addition of oregano extract (OregoStim ${ }^{\circledR}$ ) to feed. At $7.5 \mathrm{~g} / \mathrm{heifer} /$ day the latency time to approach the feed bunk was reduced by $32 \%$ but the time spent eating the concentrate was increased by $6 \%$, when compared to the control group. The authors also reported that the inclusion of the product increased the occurrence of post-ingestive licking the feed bunk, saliva production and the occurrence of sneeze events. No changes in total dry matter intake were reported. Hence, certain products in such concentrations may induce negative effects in feeding behavior and concentrate intake [80]. On another hand, the addition of the functional oils to the diets did improved animal performance and feed efficiency without important changes in the carcass characteristics or meat quality. RezaYazdi and coworkers demonstrated that an essential oil mix can be useful nutritional modification to alleviate for the decreased dry matter intake and milk production during heat exposure in lactating dairy cows [81]. Finally, Patra and Yu demonstrated that clove, eucalyptus, garlic, oregano, and peppermint

oils reduced methane production with increasing doses (decrements ranging from $17.6 \%$ to $87 \%$ ). The authors also reported a decrease in apparent degradability of dry matter and neutral detergent fiber. The concentrations of total volatile fatty acids and the molar proportions of acetate, propionate, and butyrate were affected variably by the essential oils. Quantitative real-time polymerase chain reaction and denaturing gradient gel electrophoresis demonstrate modifications in microbial community composition as well as a decrease in the abundance of archaea, protozoa, and major cellulolytic bacteria, such as, Fibrobacter succinogenes, Ruminococcus flavefaciens, and R. albus. The authors conclude that not a single essential oil (from those tested) can mitigate methane emissions but low doses in combinations with other antimethanogenic compounds could help diminish them. [82] These type of research is relevant since livestock contributions to greenhouse gas emissions is considerably high [83].

Rabbits: In another example, Koné and coworkers assessed the impact of onion, cranberry and strawberry extracts and essentials oils on rabbit meat quality. Lythrum salicaria L. (purple loosestrife) has also been used as a supplement for the rabbit [84]. The authors found that supplementation led to an increase in the total white blood cells, total volatile fatty acids, and acetic acid concentration, and a decrease in the ammonia levels while maintaining microbial diversity unaltered. They found that polyphenol-rich diets had a small but sporadic positive effect in reducing bacterial microflora. Cardinali and coworkers introduced aqueous extracts of oregano and rosemary and vitamin E into rabbit (Longissimus dorsi) feed [85]. Feed supplemented with $0.2 \mathrm{~mL} / 100 \mathrm{~g}$ extract oregano or oregano and rosemary $(0.1 \mathrm{~mL} / 100 \mathrm{~g}$, each) showed the highest final live weight and carcass weight and the best feed conversion ratio. Then, Mattioli and coworkers recently applied independently through diet a water based oregano extract, prebiotic and vitamin E to New Zealand rabbits [86]. A decrease in lipid oxidative stress was observed for all the treatments in the rabbit's loin. All feed samples modified positively to a greater extent PUFAs. All nutritional formulas led to an apt and highly nutritional rabbit meat with interesting $\omega 6 / \omega 3$ ratios.

Fish: Though not specifically an application in feed, $\mathrm{Al}$ Laham and coworkers assayed several plant extracts against antibiotic resistant Aeromonas hydrophilia which is one of the most important diseases in fish as well as an important zoonotic agent [87]. The authors demonstrated that thyme (Thymus vulgaris $\mathrm{L}$.) ethanol extract had the highest activity against said bacteria. Chakraborty and coworkers wrote an excellent review about in-feed phytochemical for fish as growth promoters and endocrine modulators [88].

Pigs: Bartoš and coworkers included commercial feed additives, Fresta F Plus (caraway and lemon oil as the main components, dried herbs and spices and quillaja saponins) and Aromex ME Plus (rosemary, thyme, and quillaja saponins) to growing-finishing pigs [89]. As low as $100 \mathrm{mg}$ additive/kg was able to improve average daily feed intake and average daily gain, reduce ammonia and carbon dioxide emissions per animal per day. The authors report that feed conversion, methane, and nitrous gas were not affected. Mohana Devi and coworkers supplemented growing pigs with extract based on Phlomis umbrosa Turcz, Cynanchum wilfordii Hemsley, Zingiber officinale Rosc, and Platycodi Radix [90]. The authors demonstrated that oil treatments could improve growth performance, nutrient digestibility, decrease fecal gas emission, and increase immune components such as white blood cells and lymphocytes, and serum insulin-like growth factor- 1 concentration. The reader is encouraged to access the paper by Thacker which describe the potential of essential oils (with the focus on eucalyptus oil) as an alternative for traditional antimicrobials in swine production [91]. 
Other species: Lee and coworkers found medicinal plants by-products could be used as a part of total ration for Hanwoo Steers [92]. A $30 \mathrm{~g} / \mathrm{kg}$ supplementation of medicinal plant byproducts demonstrated an improvement in economic efficacy in the late fattening period of the animals. Choubey and coworkers used a powdered mixture of xia xi hua (Woodfordia fruticosa (L.) Kruz, flowers, shoots, and leaves), black nightshade (Solanum nigrum L., whole plant), and fenugreek seeds (Trigonella foenum-graecum [Habl.] Disc.) [93]. This additive was added to Jamunapari goats diets and resulted in improved digestibility of all the nutrients but failed to impart any significant effect on dry matter intake or bodyweight changes. Lin and coworkers described the application of two different mixtures of essential oils (i.e. an equal mixture of clove, oregano, cinnamon, and lemon oils and a second mixture of equal parts of eugenol, carvacrol, citral and cinnamaldehyde oils) on Hu sheep via feed (1g/day) [94]. In this case, the essential oils were absorbed into microporous starch, and the resulting mixture was encapsulated with sodium alginate before use. The authors not only evaluated biochemical parameters but also measured rumen microflora using reverse transcription polymerase chain reaction. The growth of methanogens, Fibrobacter succinogenes, and Butyrivibrio fibrisolvens was inhibited. Population of fungi and Ruminococcus flavefaciens was invariable. More relevantly, the authors concluded that the addition of these mixtures did not exert adverse effects on the feed intake and digestibility of the nutrients in total or at different parts of the digestive tract. No effect was observed on rumen pH. Nevertheless, ammonia nitrogen concentration, volatile fatty acids, acetate/ propionate ratio, protozoan population and luminal protein digestibility decreased after addition of both mixtures. Propionate concentration increased. In another study, Özdoğan and coworkers, demonstrated improved results in body weights, body weight gains, total dry matter intake and feed conversion ratios, for Karya lambs (both male and female) [95]. An essential oil mixture composed of thyme leaf (Origanum onites L.), daphne leaf (Laurus nobilis L.), sage tea leaf (Salvia triloba L.), fennel seed (Foeniculum vulgare L.), orange peels (Citrus sp.) and myrtle leaf (Myrtus communis L.) oils were used. Neither, blood parameters, slaughter traits (except lung size for females) or internal organs weights were affected by the inclusion of the blend of essential oils.

\section{Conclusion}

Not without drawbacks, like any analytical technique, GC/ MS has become an ally in the identification and quantification of components from essential oils. Though there is still the need for analytical standards, MS spectra databases can help tremendously in the preliminary identification of compounds especially in those cases where the profile is complex, and no analytical resolution can be achieved for every peak. Furthermore, mass spectra can be still be elucidated by chemists as a tool for identification of unknown substances using phytochemicals as a source. So far, ample evidence shows that no single essential oil of plant-derived extract seems to be effective as a growth promoter or antimicrobial, however different blends from several oils which have demonstrated better profile and activity without affecting other animal performance parameters. Each pure oil/extract or combination must be examined individually, and each species of animals react differently even to a phytochemical. Cattle seem to be the species with most mixed results when applying essential oils as growth promoters, though some technological applications can be found mainly in the dairy industry. It is clear that the beneficial effects of essential oils or plant extracts are a result of all the mixture of compounds present in particular oil, and even synergic effects may be considered. However, organic synthesis may be a way to produce cheaply a blend that can translate as an additive which is more convenient to include within formulations for the feed industry. Especially those compounds found to have a suitable bioactive profile but are obtained from rare plant species may benefit form this approach. In this scenario, if the application essential oils or extracts are to be pursued wide spread species of plants with excellent bioactivity may be a safer bet. Furthermore, research must be continued to assess right candidates with acceptable bioactive profiles which at the same time do not alter animal well-being. Technological processes that permit incorporation of the oils into feed, in the necessary quantities, inexpensively should be explored. Edaphoclimatic changes and even regional micro variations in the environment may affect oil composition even if extracted from the same species and within a precise time frame. Some essential oils have found relative success as growth promoters, a generalized practice within the feed industry and animal production industry, this hints toward potential substitutes for antibiotics, especially since antimicrobial resistance is prevalent, is considered a health hazard and the antibiotic pipeline generate new active substances sluggishly, at best.

\section{Acknowledgement}

The Office of the Vice Provost for Research of the University of Costa Rica supported this initiative financially, by means of the grant B6257.

\section{References}

1. Zuzarte M, Salgueiro L (2015) Essential Oils Chemistry. In: de Sousa DP (Eds.), Bioactive Essential Oils and Cancer. (1 $1^{\text {st }}$ edn), Springer International Publishing, Switzerland, pp. 19-28.

2. Negi PS (2012) Plant extracts for the control of bacterial growth: Efficacy, stability and safety issues for food application. Int J Food Microbiol 156(1): 7-17.

3. Giannenas I, Bonos E, Christaki E, Florou-Paneri P (2013) Essential Oils and their Applications in Animal Nutrition. Med Aromat Plants: 2-6.

4. Ventola CL (2015) the Antibiotic Resistance Crisis Part 1: Causes and Threats. P T 40(4): 277-283.

5. Alarcon-Rojo AD, Janacua-Vidales H, Renteria MA (2017) Oregano Essential Oil in Animal Production. In: El-Shemy HA (Eds.), Active Ingredients from Aromatic and Medicinal Plants. (1 ${ }^{\text {st }}$ edn), In Tech, Croatia, pp. 226-235.

6. Kumar M, Kumar V, Roy D, Kushwaha R, Vaiswani S (2014) Application of Herbal Feed Additives in Animal Nutrition - A Review. Int J Livestock 
Res 4(9): 1-8.

7. López-Romero JC, González-Ríos H, Borges A, Simões M (2015) Antibacterial Effects and Mode of Action of Selected Essential Oils Components against Escherichia coli and Staphylococcus aureus. Evid Based Complement Alternat Med Article: 1-9.

8. SaeidiS, Boroujeni NA,Ahmadi H, Hassanshahian M (2015) Antibacterial Activity of Some Plant Extracts Against Extended- Spectrum BetaLactamase Producing Escherichia coli Isolates. Jundishapur J Microbiol 8(2): e15434.

9. Allen HK, Levine UY, Looft T, Bandrick M, Casey TA (2013) Treatment, promotion, commotion: antibiotic alternatives in food-producing animals. Trends Microbiol 21(3): 114-119.

10. Coffie GY, Antwi-Boasiako C, Darkwa NA (2014) Phytochemical constituents of the leaves of three bamboo (Poaceae) species in Ghana. Journal of Pharmacognosy and Phytochemistry 2(6): 34-38.

11. Zagorcheva T, Stanev S, Rusanov K, Atanassov I (2013) Comparative GC/MS analysis of lavender (Lavandula angustifolia Mill.) inflorescence and essential oil volatiles. Agricul Sci Tech 5(4): 459-462.

12. De Falco E, Mancini E, Roscigno G, Mignola E, Taglialatela-Scafati O, et al, (2013) Chemical Composition and Biological Activity of Essential Oils of Origanum vulgare L. subsp. vulgare L. under Different Growth Conditions. Molecules 18(12): 14948-14960.

13. Chauhan A, Goyal MK, Chauhan P (2014) GC-MS Technique and its Analytical Applications in Science and Technology. J Anal Bioanal Tech 5(6): 1-5.

14. Granados-Chinchilla F, Villegas E, Molina A, Arias C (2016) Composition, Chemical Fingerprinting and Antimicrobial Assessment of Costa Rican Cultivated Guavas (Psidium friedrichsthalianum (0. Berg) Nied. and Psidium guajava L.) Essential Oils from Leaves and Fruits. Studies Nat Prod Chem 4(5): 236.

15. De Souza T da S, Ferreira MF da S, Menini L, Souza JRC de L, Perreira LA et al. (2017) Essential oil of Psidium guajava: Influence of genotypes and environment. Sci Horticult 216: 38-44.

16. Arjouni MY, Romane A, El Fels MA, Boukir A, Algabr M (2015) Antioxidant Activity and Chemical Composition of Essential Oil of Cupressus atlantica Gaussen. Curr Bioactive Compounds 11: 56-60.

17. Béjaoui A, Chaabane H, Jemli M, Bouila A, Boussaid M (2013) Essential Oil Composition and Antibacterial Activity of Origanum vulgare subsp. glandulosum Desf. At Different Phenological Stages. J Med Food 16(12): 1115-1120.

18. Boligon AA, Feltrin AC, Gindri AL, Athayde ML (2013) Essential Oil Composition, Antioxidant and Antimicrobial Activities of Guazuma Ulmifolia from Brazil. Med Aromat Plants 2: 3.

19. Cruiz Buhian WP, Rubio RO, Valle DL, Martin-Puzon JJ (2016) bioactive metabolite profiles and antimicrobial activity of ethanolic extracts from Muntingia calabura L. leaves and stems. Asian Pac J Trop Biomed 6(8): 682-685

20. Hajdari A, Mustafa B, Nebija D, Selimi H, Veselaj Z, et al. (2016) Essential Oil Composition of Pinus peuce Griseb. Needles and Twigs from Two National Parks of Kosovo. Scientific World Journal.

21. Hanafi RS, Sobeh M, Ashour ML, El-Readi MZ, Desoukey SY, et al. Chemical Composition and Biological Activity of Essential Oils of Cumin and Coriander Fruits from Egypt. Nat Prod J 4: 63-69

22. Takayama C, de-Faria FM, de Almeida ACA, Dunder RJ, Manzo LP, et al. (2016) Chemical composition of Rosmarinus officinalis essential oil and antioxidant action against gastric damage induced by absolute ethanol in the rat. Asian Pac J Trop Biomed 6(8): 677-681.

23. Siddique AB, Mizanur RSM, Amzad HM (2016) Chemical composition of essential oil by different extraction methods and fatty acid analysis of the leaves of Stevia Rebaudiana Bertoni. Arab J Chem 9: 1185-1189.
24. Yang C, Chowdhury MAK, Hou Y, Gong J (2015) Phytogenic Compounds as Alternatives to In-Feed Antibiotics: Potentials and Challenges in Application. Pathogens 4(1): 137-156.

25. Castillo-López RJ, Gutiérrez-Grijalva EP, Leyva-López N, LópezMartínez LX, Heredia JB (2017) Natural alternatives to growthpromoting antibiotics (GPA) in animal production. J Anim Plant Sci 27(2): 349-359.

26. Cochrane RA, Huss AR, Aldrich GC, Stark CR, Jones CK (2016) Evaluating Chemical Mitigation of Salmonella Typhimurium ATCC 14028 in Animal Feed Ingredients. J Food Prot 79(4): 672-676.

27. Bianchini A, Stratton J, Weier S, Cano C, Garcia LM (2014) Use of Essential Oils and Plant Extracts to Control Microbial Contamination in Pet Food Products. J Food Process Technol 5: 8

28. Rajendran MP, Pallaiyan BB, Selvaraj N (2013) Chemical composition, antibacterial and antioxidant profile of essential oil from Murraya koenigii (L.) leaves. Avicenna J Phytomed 4(3): 200-214.

29. Saeidi S, Amini Boroujeni N, Ahmadi H, Hassanshahian M (2015) Antibacterial Activity of Some Plant Extracts against ExtendedSpectrum Beta-Lactamase Producing Escherichia coli Isolates. Jundishapur J Microbiol 8(2): e15434.

30. Mostafa AA, Al-Askara AA, Dawouda TM, Sholkamya EN, Bakric MM (2017) Antimicrobial activity of some plant extracts against bacterial strains causing food poisoning diseases. Saudi J Biol Sci.

31. Ginovyan M, Petrosyan M, Trchounian A (2017) Antimicrobial activity of some plant materials used in Armenian traditional medicine. BMC Complement Altern Med 17(1): 50.

32. Mith H, Duré R, Delcenserie V, Zhiri A, Daube G et al.(2014) Antimicrobial activities of commercial essential oils and their components against food-borne pathogens and food spoilage bacteria. Food Sci Nutr 2(4): 403-416.

33. Ozogul Y, Kuley E, Uçar Y, Ozogul F (2015) Antimicrobial Impacts of Essential Oils on Food Borne-Pathogens. Recent Pat Food Nutr Agric 7: 53-61.

34. Manjula G, Chitra T (2017) Studies on qualitative and quantitative phytochemical analysis of plants Calotropis gigantean and Curcuma neilgherrensis. WJPPS 6(3): 542-551.

35. Venkatesa A, Kathivel A, Prakash S, Sujatha V (2017) Antioxidant, Antibacterial Activities and Identification of Bioactive Compounds from Terminalia chebula Bark Extracts. Free Radicals and Antioxidants 7(1): 43-49.

36. Salaheen S, Jaiswal, E, Joo J, Peng M, Ho R, et al. (2016) Bioactive extracts from berry byproducts on the pathogenicity of Salmonella Typhimurium. Int J Food Microbiol 237: 128-135.

37. Yang H, Hewes D, Salaheen S, Federman C, Biswas D (2014) Effects of blackberry juice on growth inhibition of foodborne pathogens and growth promotion of Lactobacillus. Food Control 37: 15-20.

38. .Salaheen S, Nguyen C, Hewes D, Biswas D (2014) Cheap extraction of antibacterial compounds of berry pomace and their mode of action against the pathogen Campylobacter jejuni. Food Control 46:174-181

39. Manjula G, Chitra T (2017) Studies on qualitative and quantitative phytochemical analysis of plants Calotropis gigantean and Curcuma neilgherrensis. WJPPS 6(3): 542-551.

40. Bento MHL, Ouwehand AC, Tiihonen K, Lahtinen S, Nurminen P, et al. (2013) Essential oils and their use in animal feeds for monogastric animals-Effects on feed quality, gut microbiota, growth performance and food safety: a review. Veterinarni Medicina 58(9): 449-458.

41. Zheng Z, Zhang S, Wang H, Piao X (2015) Essential oil and aromatic plants as feed additives in non-ruminant nutrition: a review. J Anim Sci Biotech 6(1): 7. 
42. Upadhaya SD, Kim IH (2016) Efficacy of phytogenic feed additive on performance, production and health status of monogastric animals - a review. Ann Anim Sci.

43. Adrian JA, Arancon NQ Mathews BW, Carpenter JR (2012) proximate analysis, in vitro organic matter digestibility, and energy content of common guava (Psidium guajava L.) and yellow, strawberry guava (Psidium cattleianum Var. lucidum) tree parts and fruits as potential for age. J Agric Food Chem 60: 10398-10405.

44. Mahmoud R, Ibrahim D, Badawi M (2003) Effect of supplementation of broiler diets with guava leaves and/or olive oil on growth, blood metabolites and immune response. Benha Veterinary Medical Journal 25: 23-32.

45. Shen SC, Cheng FC, Wu NJ (2008) Effect of Guava (Psidium guajava Linn.) Leaf Soluble Solids on Glucose Metabolism in Type 2 Diabetic Rats. Phytother Res 22(11): 1458-1464.

46. Shalaby SM, Mohamed AG, Bayoumi HM (2017) Preparation of a Novel Processed Cheese Sauce Flavored with Essential Oils. Int J Dairy Sci 12: 161-169.

47. Lejonklev J, Storm AC, Larsen MK, Mortensen G, Weisbjerg MR (2013) Differences in rate of ruminal hydrogenation of C18 fatty acids in clover and ryegrass. Animal 7(10): 1607-1613.

48. Lejonklev J, Løkke MM, Larse MK, Mortensen G, Petersen MA et al. (2013) Transfer of terpenes from essential oils into cow's milk. J Dairy Sci 96: 4235-4241.

49. Lejonklev J, Kidmose U, Jensen S, Petersen MA, Helwing AL, et al. (2016) Short communication: Effect of oregano and caraway essential oils on the production and flavor of cow milk. J Dairy Sci 99(10): 7898-903.

50. Krisch J, Tserennadmid R, Vágvölgyi C (2011) Essential oils against yeasts and moulds causing food spoilage. In: Méndez-Vilas (Eds.) Science against microbial pathogens: communicating current research and technological advances. ( $1^{\text {st }}$ edn). Formatex Research Center, Spain, pp. 1135-1142.

51. Tongnuanchan P, Benjakul S (2014) Essential Oils: Extraction, Bioactivities, and Their Uses for Food Preservation. J Food Sci 79(7): R1231-R1249.

52. Shahavi MH, Hosseini M, Jahanshahi M, Meyer RL, Darzi GN (2016) Clove oil nanoemulsion as an effective antibacterial agent: Taguchi optimization method. J Des Water Treat 57(39): 18379-18390.

53. Karásková K, Suchý P, Straková E (2015) Current use of phytogenic feed additives in animal nutrition: a review. Czech J Anim Sci 60(12): 521530.

54. Palmer-Young EC, Sadd BM, Irwin RE, Adler LS (2017) Synergistic effects of floral phytochemicals against a bumble bee parasite. Ecol Evol 7(6): 1836-1849.

55. Duncan A, Magalhães S (2017) the medicinal value of phytochemicals is hindered by pathogen evolution of resistance. Peer Community in Evolutionary Biology.

56. Kasapidou E, Sossidou E, Mitlianga P (2015) Fruit and Vegetable CoProducts as Functional Feed Ingredients in Farm Animal Nutrition for Improved Product Quality. Agriculture 5: 1020-1034.

57. Lu W, Wang J, Zhang HJ, Wu SG, Qi GH (2016) Evaluation of Moringa oleifera leaf in laying hens: effects on laying performance, egg quality, plasma biochemistry and organ histopathological indices. Ital J Anim Sci 15(4): 658-665.

58. Jiang XR, Zhang HJ, Wang J, Wu SG, Yue HY, et al. (2016) Effect of dried tangerine peel extract supplementation on the growth performance and antioxidant status of broiler chicks. Ital J Anim Sci 15(4): 642-648.

59. Vongsak B, Sithisarn P, Mangmool S, Thongpraditchote S, Wongkrajang Y et al. (2013) Maximizing total phenolics, total flavonoids contents and antioxidant activity of Moringa oleifera leaf extract by the appropriate extraction method. Industrial Crops and Products 44: 566-571.

60. Mohammadi Z, Ghazanfari S, Moradi MA (2014) Effect of supplementing clove essential oil to the diet on microflora population, intestinal morphology, blood parameters and performance of broilers. Europ Poult Sci 78

61. Valenzuela-Grijalva NV, Pinelli-Saavedra A, Muhlia-Almazan A Domínguez-Díaz D, González-Ríos H (2017) Dietary inclusion effects of phytochemicals as growth promoters in animal production. J Anim Sci Technol 59: 8

62. Peek HW, Halkes SBA, Tomassen MMM, Mes JJ, Landman WJM (2013) In vivo screening of five phytochemicals/extracts and a fungal immunomodulatory protein against colibacillosis in broilers.Avian Pathol, 42(3): 235-247.

63. Alp M, Midilli M, Kocabağlı N, Yılmaz H, Turan N et al. (2012) The effects of dietary oregano essential oil on live performance, carcass yield, serum immunoglobulin G level, and oocyst count in broilers. J Appl Poult Res 21: 630-636.

64. Surai PF (2013) Polyphenol compounds in the chicken/animal diet: from the past to the future. J Anim Phys Anim Nutr 98(1): 19-31.

65. Adaszyńska-Skwirzyńska M, Szczerbińska D (2017) Use of essential oils in broiler chicken production - a review. Ann Anim Sci 17(2): 317335.

66. Çabuk M, Serdar Eratak S, Alçicek A, Bozkurt M (2014) Effects of Herbal Essential Oil Mixture as a Dietary Supplement on Egg Production in Quail. Scientific World Journal :1-4.

67. Küçükyilmaz K, Kiyma Z, Akdağ A, Çetinkaya M, Atalay H et al. (2017) Effect of lavender (Lavandula Stoechas) essential oil on growth performance, carcass characteristics, meat quality and antioxidant status of broilers. South African J Anim Sci 47(2): 178-186.

68. Rendon MDM, Acda SP, Magpantay VA, Fajardo NN, Angeles AA (2015) Essential Oil Blend Containing Capsaicin, Carvacrol and Cinnamaldehyde in Broiler Production Performance and Intestinal Morphometrics. International Scholarly and Scientific Research \& Innovation 9(12): 1218-1221.

69. Garnett $T$ (2010) Intensive versus extensive livestock systems and greenhouse gas emissions. FCRN briefing paper.

70. Oskoueian E, Abdullah N, Oskoueian A (2013) Effects of Flavonoids on Rumen Fermentation Activity, Methane Production, and Microbial Population. Biomed Res Int: 1-8.

71. Patra AK, Yu Z (2012) Effects of Essential Oils on Methane Production and Fermentation by, and Abundance and Diversity of, Rumen Microbial Populations. App Environ Microbiol 78(12):4271-4280.

72. Vakili AR, Khorrami B, Mesgaran MD, Parand E (2013) The Effects of Thyme and Cinnamon Essential Oils on Performance, Rumen Fermentation and Blood Metabolites in Holstein Calves Consuming High Concentrate Diet. Asian Australas J Anim Sci 26(7): 935-944.

73. Islam RU, Khan MA, Islam SU (2016) Plant derivatives as promising materials for processing and packaging of meat-based products - focus on antioxidant and antimicrobial effects. J Food Process Preserv.

74. Barreto Cruz OT, Valero MV, Zawadzki F, Rivaroli DC, do Prado RM, et al. (2014) Effect of Glycerine and Essential Oils (Anacardium Occidentale and Ricinus Communis) on Animal Performance, Feed Efficiency and Carcass Characteristics of Crossbred Bulls Finished in a Feedlot System. Ital J Anim Sci 13(4): 3492.

75. Gunal M, Ishlak A, AbuGhazaleh AA, Khattab W (2014) Essential oils effect on rumen fermentation and biohydrogenation under in vitro conditions. Czech J Anim Sci 59(10): 450-459.

76. Valero MV, do Prado RM, Zawadzki F, Eiras CE, Madrona GS, et al. (2014) Propolis and essential oils additives in the diets improved animal performance and feed efficiency of bulls finished in feed lot. Acta Sci 
Amin Sci 36(4): 419-426.

77. Reza-Yazdi K, Fallah M, Khodaparast M, Kateb F, Hosseini-Ghaffari M (2014) Effects of Specific Essential Oil Compounds on, Feed Intake, Milk Production, and Ruminal Environment in Dairy Cows during Heat Exposure. Int J Biol, Vet, and Agric Food Eng 8(12): 1242-1245.

78. Kolling GJ, Panazzolo DJ, Gabbi AM, Stumpf MT, dos Passos MB, da Cruz EA, Fischer V (2016) Oregano Extract Added into the Diet of Dairy Heifers Changes Feeding Behavior and Concentrate Intake. Sci World J Article ID 8917817.

79. Koné AP, Cinq-Mars D, Desjardins Y, Guay F, Gosselin A, et al. (2013) Effects of plant extracts and essential oils as feed supplements on quality and microbial traits of rabbit meat. World Rabbit Sci 24: 107119.

80. Cardinali R, Cullere M, Dal Bosco A, Mugnai C, Ruggeri S, et al. (2015) Oregano, rosemary and vitamin $\mathrm{E}$ dietary supplementation in growing rabbits: Effect on growth performance, carcass traits, bone development and meat chemical composition. Livestock Sci 175: 8389.

81. Joch M, Cermak L, Hakl J, Hucko, B, Duskova D et al. (2016) In vitro Screening of Essential Oil Active Compounds for Manipulation of Rumen Fermentation and Methane Mitigation. Asian Australas J Anim Sci 29(7): 952-959

82. Mattioli S, Cardinali R, Balzano M, Pacetti D, Castellini C, et al. (2017) Influence of Dietary Supplementation with Prebiotic, Oregano Extract, and Vitamin E on Fatty Acid Profile and Oxidative Status of Rabbit Meat. J Food Quality: 1-9.

83. Aguirre-Villegas H, Larson RA, Ruark MD (2016) Methane emissions from dairy cattle - An overview. Sustainable Dairy Available from: https://learningstore.uwex.edu/Assets/pdfs/A4131-01.pdf Accessed: September 2017

84. Al Laham SA, Al Fadel FM (2014) Antibacterial Activity of Various Plants Extracts against Antibiotic-resistant. Jundishapur J Microbiol 7(7): e11370
85. Chakraborty SB Horn P Hancz C (2013) Application of phytochemicals as growth-promoters and endocrine modulators in fish culture. Rev Aquacult 5: 1-19.

86. Bartoš P, Dolan A, Smutný L, Šístková M, Celjak I, et al. (2016) Effects of phytogenic feed additives on growth performance and on ammonia and greenhouse gases emissions in growing-finishing pigs. Anim Feed Sci Technol 212: 143-148.

87. Devi SM, Park JW, Kim IH (2015) Effect of plant extracts on growth performance and insulin-like growth factor 1 secretion in growing pigs. R Bras Zootec, 44(10): 355-360.

88. Thacker PA (2013) Alternatives to antibiotics as growth promoters for use in swine production: a review. J Anim Sci Biotechnol 4: 35.

89. Lee SJ, Kim DH, Guan LL, Ahn SK, Cho KW, et al. (2015) Effect of Medicinal Plant By-products Supplementation to Total Mixed Ration on Growth Performance, Carcass Characteristics and Economic Efficacy in the Late Fattening Period of Hanwoo Steers. Asian-Australas J Anim Sci 28(12): 1729-1735.

90. Choubey M, Pattanaik AK, Baliyan S, Dutta N, Jadhav SE, et al. (2015) Dietary supplementation of a novel phytogenic feed additive: effects on nutrient metabolism, antioxidant status and immune response of goats. Anim Prod Sci 56:1612-1621.

91. Lin B, Lua Y, Salem AZM, Wang JH, Liang Q et al. (2013) Effects of essential oil combinations on sheep ruminal fermentation and digestibility of a diet with fumarate included. Anim Sci Feed Technol 184: 24-32.

92. Özdoğan M, Önenç SS, Önenç A (2011) Fattening performance, blood parameters and slaughter traits of Karya lambs consuming blend of essential oil compounds. African J Biotechnol 10(34): 6663-6669.

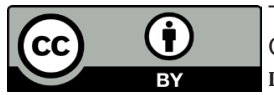

This work is licensed under Creative

Commons Attribution 4.0 Licens

DOI: $10.19080 /$ JDVS.2017.03.555620 